\title{
1. Introduction: reimagining ways of talking about the Anthropocene
}

\author{
Anu Valtonen and Outi Rantala
}

\section{THE ANTHROPOCENE?}

In the current epoch, known as the Anthropocene, humans interfere with the geological and biological processes of the world to a greater extent and at a faster rate than ever before. The term was coined by Nobel laureate Paul Crutzen (2002), and it is commonly used to refer to a range of human-induced phenomena, such as climate change, mass extinction of species and the pollution of the oceans and the air, which all have profound consequences for the wellbeing of every inhabitant of the earth (Crutzen \& Stoermer, 2000; Hamilton, 2016; Wright et al., 2018).

While it is a contested term (Malm \& Hornborg, 2014), the 'Anthropocene' has aroused an upsurge of interest in the natural and social sciences, as well as in fields across the arts and humanities. As a result, journals dedicated to the topic, such as Anthropocene and The Anthropocene Review, have been launched, several collaborative projects and seminars have been organised, a wealth of books, articles and special issues have been published (e.g. Angus, 2016; Grusin, 2017; Tsing et al., 2017) and courses on the Anthropocene have been included in the curricula of higher education around the world. Furthermore, a range of diverse cultural projects engaging with the idea of the Anthropocene has been organised all over the globe, such as art exhibitions, performances, theatre plays and podcasts. We have also witnessed the emergence of grassroots activism aiming to change ineffectual political and economic efforts to transform current modes of living. The world-scale movement initiated by 16-year-old Greta Thunberg provides a case in point.

These burgeoning activities act as evidence that the Anthropocene is more than merely a term for an epoch (Toivanen et al., 2017); it has proved to be a malleable concept used in creative ways in different contexts. Perhaps most importantly, it has raised much-needed awareness about the magnitude of the environmental problems concerning the earth, inspired people to act and provided an umbrella term that enables people representing different backgrounds 
and fields to collaborate in solving urgent earthly problems. The debate has also deepened common knowledge of the complexity of the ongoing transformation. It has highlighted that all planetary subsystems are deeply interconnected, rendering visible the fact that the whole earth, from its crust to the outermost reaches of its atmosphere, has been profoundly disrupted by human activities (Wright et al., 2018, p. 457). In academia, the Anthropocene has facilitated cooperation between disciplines, in particular between the natural and social sciences. It has pushed scholars representing different disciplines to search for a common ground that would enable them to work together instead of falling into the 'science wars'. The development of geosocial perspectives integrated with geological and social-scientific insights provides a good example (Clark \& Yusoff, 2017). The planetary situation clearly demands this kind of collaborative effort.

\section{THE ANTHROPOCENE AS A CRISIS OF THINKING}

As the above discussion suggests, alongside the ecological crisis, the Anthropocene articulates a crisis of thinking (Zylinska, 2014, p. 19). It poses a range of intellectual challenges to scholars, inviting them to develop a greater degree of critical reflexivity (Wright et al., 2018). This relates, in particular, to the assumptions inscribed in the commonly used conceptual categories through which human-nature relations are considered. The debate has rendered strikingly evident the fact that 'natural' and 'cultural' entangle in so many ways that their separation must - at last - be questioned, and novel formulations introduced.

Nature and culture are so inextricably intertwined in our bodies, our landscapes, our technologies and our ways of doing research that the artificial and harmful (yet persistent) division merits bridging. The debate has also called into question the human-centric foci of much of social-scientific research - as well as the question of the 'human' in the Anthropocene. While humans are considered geological forces, and the very term focalises human impact on the earth, not 'all humans', but a small a powerful subset living in the global north, are primarily responsible for the crisis. The activities of this group are fuelled by global corporate capitalism, which is reliant upon continued growth, ever-expanding consumption and the use of fossil fuel based energy (Angus, 2016; Malm, 2016; Moore, 2016; Salminen \& Vaden, 2015). Furthermore, the Anthropocene demands new reflection on the very category of human, which commonly rests on a distinction between biology and culture (Frost, 2016; Haraway, 2016). By challenging the fantasy of human as separate from inhuman, Frost (2016), for instance, proposes a conceptualisation of humans as biocultural creatures, and in so doing opens up one possible avenue for challenging the human exceptionalism enshrined in disciplinary categories. 
She elucidates the imbrication of the biological and cultural within the corporeal self, building thereby a bridge between humanities and the sciences. In the same vein, Wright and his colleagues (2018) remark that 'purely inhuman nature - the imagined object of most science - was never a valid construct because the human was always an inextricable element in the view of nature' (p. 457).

This debate has hence encouraged social-scientific scholars to think beyond the dichotomy of nature and culture and to recognise that there is a plethora of other species and creatures living on the same planet besides the one named humans. Many scholars have recently argued for the need to accord more-than-humans expanded agential status in social-scientific inquires instead of treating them as 'resources' or as having the role of merely 'serving human needs'. As a result, we have witnessed an increasing number of social-scientific studies that include more-than-humans in their inquiries and make much-needed efforts to find conceptualisations apt for thinking about how different earthly creatures could, and should, coexist and co-live as kin (e.g. Haraway, 2016; Kalonaityte, 2018; Lorimer, 2015; Puig de la Bellacasa, 2015; Tsing et al., 2017). Furthermore, the development of novel pedagogies (Jickling et al., 2018) and methods that enable the exploration of life and coexistence in a more-than-human world is underway (e.g. Salmela \& Valtonen, 2019; Springgay \& Truman, 2018; Ulmer, 2017). All in all, then, the Anthropocene has stimulated a necessary reflection on the ontological, epistemological and methodological assumptions that underpin social-scientific knowledge production.

In continuing this timely debate, this book focuses on discussing the Anthropocene through the concepts of ethics and politics by emphasising the question of space. Many issues of the Anthropocene revolve around the question of how space between the human sphere and the rest of the world is, or is not, shared - an ethical and political question in itself. Furthermore, the Anthropocene profoundly challenges the temporal and spatial horizons of ethical actions, rousing novel ethical concerns. Indeed, the ontologies of space radically affect the episteme through which human-earth relations are understood, challenging the conventional norms for coexistence between various inhabitants of the earth. The Anthropocene also invites us to reassess the often Eurocentric, rationalistic and human-centred assumptions baked into ethical theories and to explore conceptual and practical links between ethics and politics. This book therefore seeks to consider the scope of such ethical and political analyses in a broad sense to better capture the complex and novel nature of these ongoing transformations. It thereby expands the important openings made by previous scholars (e.g. Biermann, 2014; Schmidt et al., 2016). The guiding question of the book, therefore, reads as: how should the ethics and politics of space be thought about in the current epoch? In answering this 
question the book asks, and tries to address, more detailed questions such as what does this mean conceptually, politically and empirically? For instance, how should we think about ethics when applied not only to humans but also to more-than-humans (Beacham, 2018; Kinnunen \& Valtonen, 2017; Puig de la Bellacasa, 2015; Zylinska, 2014)? How, then, ought ethical relations between various inhabitants of the earth be reimagined? For instance, what does it mean for energy politics if we acknowledge that the social and biological intertwine?

To address these pressing questions, this book draws inspiration from several up-to-date theoretical sources. For instance, the recent new materialist and post-colonialist literatures, which challenge the Western, rational view of science and ethics, enable us to better address the social, political and environmental injustices that different regions of the world are facing and to develop more just, localised solutions (Seppälä, 2016). They also provide apt conceptual tools for capturing the complex ways that the social and cultural, humans and more-than-humans, are intertwined (Rantala et al., 2019). The book also places much emphasis on the lived and embodied experiences of people to grasp how the Anthropocene is felt and lived in different spaces and places around the globe. The narrative nature of the Anthropocene concept forms another crucial characteristic that underpins this book. As narratives have performative qualities, causing people to think and act in a particular way, it is vital to carefully reflect on the narratives that scholars, among other groups, tell.

\section{NARRATIVES OF THE ANTHROPOCENE}

While the Anthropocene, as a condition, motivates all the chapters of this book, it is primarily the narrative aspect that connects them. Prior scholars have identified a range of narratives that inform the way the Anthropocene is thought about and acted upon. The Anthropocene opens up an evolutionary narrative in itself, which 'reimagines human origins and endings within a geologic rather than an exclusively biological context' (Yusoff, 2016, p. 3). In so doing, it radically rewrites concepts of life, moving 'from predominantly biopolitical notions of life toward an understanding of life's geophysical origination (geontics)' (Yusoff, 2016, p. 3). The basic narrative also involves a debate about the beginning of the Anthropocene, and casts several symbolic steps, such as the Industrial Revolution and the Great Acceleration that followed the Second World War, as key markers of the transformation. The end, for the narrative's part, is concerned with the future of humanity, or the planet after humans, displaying either a 'good Anthropocene' with 'happy endings' or more dystopian and apocalyptic alternatives (Toivanen et al., 2017).

On the other hand, the 'business-as-usual' narrative downplays or even denies the existence of an earthly crisis. Advocates of such a narrative (i.e. 
global corporations and political elites) continue to rely on the current neoliberal agenda valuing business expansion and growth and viewing the earth as 'simply a source of natural resources and a sink for the disposal of our economies' (Wright et al., 2018, p. 460). The 'techno-rational' narrative, in turn, portrays the crisis as a business opportunity, based on the optimistic belief that new technology, corporate innovations, economic development and markets can enable the minimisation of planetary harm and ultimately remake the world (for a critique, see e.g. Heikkurinen, 2017; Wright et al., 2018). The heroic role accorded to markets and technology is visible, for instance, in the development of new green products, green technology and geoengineering. This narrative thus promotes the view that these problems can be solved by the same means that caused them in the first place.

In contrast to worldviews portrayed in these two narratives, this book advocates - as do many others (Wright et al., 2018; Heikkurinen, 2017) - a more radical reimagination of prevalent economic and social structures, as well as associated systems of belief. It also promotes a plurality of narratives about the Anthropocene, rather than a single grand narrative. Here, plurality refers to the range of voices represented in the narratives: voices from different spheres of the world, from different groups of people in terms of class, gender and ethnicity, from activists and from those who are most vulnerable to the crisis. The 'voice' of the more-than-humans must be included. With plurality, we also refer to the worldviews exhibited in these narratives - and the very style of narrating as such. Reimaging ways of telling narratives about the Anthropocene, such as through the arts, is an important step, as it offers a new and potentially far more extensive way of 'seeing, sensing, thinking, and dreaming that creates the conditions for material interventions in, and political sensibilities of the world' (Yusoff \& Gabrys, 2011, p. 516; see Wright et al., 2018, pp. 464-465). As Zylinska notes (2014, p. 11), stories have a performative nature: they can enact, not just describe, things. They have the power to promise some futures and conceal others. The work of telling new stories is not an easy practice; it requires ongoing engagement and a willingness to unpack the social, disciplinary and ideological structures within which we are embedded (Loveless, 2019, p. 20).

\section{TOWARD SITUATED NARRATIVES IN A MORE-THAN-HUMAN WORLD}

The uniqueness of this book lies in the fact that it outlines new and more radical ways of addressing the current crisis. To this end, it envisages a narrative of change that renders visible the range of transformations taking place throughout the globe. This allows us, we posit, to better capture the complex nature of these ongoing transformations, and to alter unjust practices 
and power structures in a more sustainable and context-specific manner. Importantly, this new narrative highlights the localised and situated nature of the Anthropocene, allowing the differences between regions and contexts - and subsequent ethical and political questions - to be taken seriously. In other words, such a view urges us to discuss ethics in specific social, political, environmental and cultural contexts (Cui \& Xu, 2019). It also highlights the potentiality residing in non-Western ways of relating to and living on the earth, taking more-than-humans into account.

Ontologically, this book challenges the practice of assigning different forms of life to normatively fixed roles and categories, engaging instead in thinking about the world in terms of continuity, openness and messiness. This ontology functions as the inspiration for conceptual innovation. This book employs and develops a number of concepts that open up intriguing insights into the ethics and politics of space in the Anthropocene. To illustrate, concepts such as more-than-human care, scientific fabulation, prefigurative epistemologies, resistance, activism, technologies, sacredness and human-energy-nature relationships invite the reader to engage in critical reflection about how to tackle the earthy crisis.

Thus, the core pillars that form the base of the narrative outlined in this book are (1) the generation of situated in-depth knowledge, (2) the recognition of non-Western knowledge and (3) the entanglement of humans and more-than-humans. Next, we elaborate on these pillars.

\section{Situated In-Depth Knowledge}

Due to the dominant role of the natural sciences in defining the Anthropocene, and the earth-level scale inscribed into the very concept, many studies have produced macro-level analyses based upon natural-scientific, statistical and quantitative methods and measures. While this kind of knowledge is vitally important, no doubt, and widely used in well-known reports and studies, such as those of the Intergovernmental Panel on Climate Change (IPCC) and the Global Footprint Network, it seems to be ineffective in eliciting change (Bonnedahl \& Heikkurinen, 2018). Much of the diverse social and cultural phenomena related to the Anthropocene are, indeed, resistant to modelling (Palsson et al., 2013, p. 6). Furthermore, such a macro-level approach creates a homogenising and universalising account of the earth, neglecting the vast biological, geographical and social particularities, inequalities and complexities of different regions and contexts. Therefore, there is a pressing need for more situated and localised analyses of the Anthropocene, as noted by many (Biermann et al., 2016; Palsson \& Swanson, 2016). Moreover, Forrest Clingerman (Chapter 2 in this book) calls for emplaced analyses, arguing that 'participation in political life is possible only when political action recognizes 
and upholds the need to flourish in a location, context, or place'. These situated analyses necessitate the development and employment of methods suitable for enabling the provision of in-depth and down-to-earth knowledge of the social and environmental changes taking place in different regions, as well as for gaining an understanding of how these changes are lived-with and experienced by different groups.

The chapters in this book respond to this challenge by offering situated and empirically well-grounded analyses of various places and spaces around the globe. The offered analyses remain sensitive to the biological, geological and social - as well as ethical and political - particularities and complexities of the places in question. The chapters also exemplify the use of a range of methods that enable researchers to grasp how human-nature relations are articulated in these places at a grassroots level. For instance, Outi Rantala, Anu Valtonen and Tarja Salmela (Chapter 3) explore the lively relationalities between human bodies and rocks by employing the walking method (Springgay \& Truman, 2018) in the context of a national park situated in Finnish Lapland. Their chapter also articulates a different story than is commonly told about the Arctic, of which Finnish Lapland is a part. Staging rocks, instead of melting ice and polar bears, illustrates how small, situated stories can provide a more nuanced picture of life lived and experienced in the Anthropocene.

The power of small, situated stories is further highlighted by the study of Emily Höckert (Chapter 4). By using the familiar practice of telling fairy tales, she sets out to reimagine the practice of storytelling and story-listening in the Anthropocene. The chapter deliberates on the ways in which scientific fables would allow us to gather around matters of care in more-than-human worlds. The introduced conceptual innovation of scientific fabulation allows multiple voices to be involved in the narrative of the Anthropocene and regards complicating, specifying, slowing down and hesitating as important aspects of narration. Such notions give voices to more-than-humans, an act that is urgently needed, and creates new forms of language and representation that help to speculate on the futures of humanity and the planet.

Afroja Khanam and Tiina Seppälä (Chapter 5) and Paul Routledge (Chapter 6 ), in turn, bring us to Bangladesh, one of the countries in the world most vulnerable to the impacts of climate change and rising sea levels. Khanam and Seppälä analyse the injustices faced by displaced people and communities in two slums in Dhaka. Throughout their in-depth fieldwork, they use a mixture of qualitative methods (e.g. interviews, observations, group discussions) to give voices to marginalised people and to highlight the forms of resistance and grassroots activism they enacted to take agency. Routledge's study, for its part, is based upon a prolonged ethnographic and collaborative engagement with two rural-based peasant movements in Bangladesh. It presents politically engaged research among the rural poor. By highlighting - and contesting - 
unequal social and environmental relations, as well as the historical legacy behind them, his study works toward an ethical politics of climate justice that acts through interventions. Then, in Chapter 7, Arbita Bisht gives a voice to the Adivasis, the indigenous people of India, many of whom are dispossessed of their land due to 'development' projects. She presents a document-based analysis of ecological distribution conflicts related to mineral extraction, highlighting social resistance movements that aim at defending the cultural and sacred spaces of Adivasi communities against exploitation.

All these chapters contest the capitalist, growth-based and techno-oriented business-as-usual narrative, demonstrating how it brings about uneven solutions both socially and environmentally in different local contexts. In contrast, the chapters highlight how local-level activism, interventions, resistances and social movements can be mobilised to work toward justice, equality, dignity and rights. They also demonstrate how local-level resistance can act as a powerful mediator of transformation. In so doing, they exemplify how the alternative narrative of the Anthropocene that includes political action, protest, civil disobedience and community engagement is put into practice (Wright et al., 2018, p. 463). Altogether, these contributions provide a rich body of contextual understanding from different places and spaces around the world, entangling with social, legislative, ethical and political issues.

Furthermore, in Chapter 10, Paolo Davide Farah and Marek Prityi highlight the role of agile governance in addressing 'wicked problems' related to the Anthropocene, such as climate change. They argue that agile governance systems must include a broad array of stakeholders with both vertical and horizontal governance backgrounds - from local, state, national and international levels to the private, public and non-governmental organisation (NGO) sectors. These forms of governance, based solely on collaboration, aim to ensure that democratic principles are not compromised as a result of the need to address the issues presented by the Anthropocene. Seen from the perspective of 'the knowledge generation', stakeholder collaboration may allow access to the expertise necessary to combat false narratives. In the context of the global north-south divide, collaborative approaches harness the potential to improve both mitigative and adaptive paradigms for addressing climate change. In so doing, the chapter illustrates the way geographical and social particularities, inequalities and complexities of different regions and contexts could be taken into account when earthly challenges are addressed.

\section{Recognising Non-Western Knowledge}

Many scholars have raised concerns that the narrative of the Anthropocene continues to reproduce the Western - and masculine - rationalistic worldview (e.g. Springgay \& Truman, 2018). This is strikingly visible in the 
techno-rational narrative that assumes environmental problems should, and could, be solved by technology. As Grusin (2017) points out:

Scientists and engineers continue to rely on many of the same masculinist and human-centred solutions that have created the problems in the first place, whether through offsetting carbon emissions, by developing new and cleaner energy sources, or, most dramatically, through heroic agency of geoengineering. (p. ix)

Furthermore, environmental politics scholar Lövbrand (Wright et al., 2018) aptly notes that the concept of the Anthropocene has emerged within a historically situated context dominated by modernist and masculinist forms of science, which contributes to proposed science-led solutions, such as geoengineering.

Relying on a Western, rationalist view of science and knowledge is also problematic, as it downplays different worldviews and understandings of knowledge, including local and indigenous knowledge. As a result, while the people of the global south are dramatically affected by the economic and political activities of those of the global north, their own knowledge and ways of thinking about nature-culture relations is not given adequate value or recognition. To overcome this scientific bias, Zylinska (2014, pp. 14-15) talks about a 'post-masculinist rationality' and 'post-masculinist politics'. The aim is not, then, to exert control over everything through the force of instrumental rationality, but rather to face the uncertainty, the unpredictable and speculative nature of things (see also Puig de la Bellacasa, 2012). This book aligns with this suggestion; it responds to Western rationalism by giving a voice to non-Western people and their own worldviews and systems of belief and by employing theoretical sources that depart from the masculinist, rational modes of science.

As exemplified in the above-mentioned studies conducted in Bangladesh and India, voices are given to the marginalised people of the global south. The study of Bisht on the Adivasi indigenous community (Chapter 7) brings to the fore a worldview that contrasts with the prevalent Western one. For the Adivasis, nature has value in itself: their cultural identity, livelihood, ways of living and social structures are deeply embedded within local ecosystems. No wonder, then, that they face conflicts with the economically and politically powerful groups for whom nature - forests and minerals - represents merely monetary value. Khanam and Seppälä (Chapter 5), for their part, base their study on slum communities in Dhaka on the epistemological conviction that researchers must listen to the voices of the excluded and marginalised. Importantly, instead of theorising about them from a distance, they try rather to build theory with them, in dialogue. This epistemological approach, informed by the post-colonial theorist Motta (2011) in particular, seeks to transcend the 
binary between theoretical and practical knowledge, challenging, in particular, the presumption that the researcher has 'the epistemic privilege' in producing theoretical knowledge. Rather, in prefigurative epistemologies, as their approach is called, theory is produced collectively via reflection and is based upon the lived experiences and struggles of excluded and marginalised communities. Speaking and theorising from the epistemological margins provides one way of leveraging more equal and sustainable insights for policymaking.

Post-colonial theories, together with lived experiences, are also employed by Höckert (Chapter 4), who uses them to challenge the idea of knowledge as completed and distanced, as well as to unpack the often problematic natureculture or human-animal relations portrayed in fairy tales, which perpetuate the Western economic worldviews underpinning these stories. The dominant legacy of science is further challenged by Rantala, Valtonen and Salmela (Chapter 3), who draw from feminist new materialist literature to problematise and refigure human-nature relations.

\section{The Entanglement of Humans and More-Than-Humans}

The Anthropocene has accentuated the need to recognise and retheorise the more-than-human inhabitants of the earth, such as animals, plants, trees, minerals or bacteria (Haraway, 2016; Lorimer, 2015). While there has been a tendency in the Western scientific legacy to think of humans and more-than-humans as separate entities, and to accord active agency only to the former, recent theorisations have challenged this assumption. Barad (2003), among others (Alaimo \& Hekman 2008; Bennett, 2010), has forcefully argued for the need to grant agency to more-than-humans and to think of the relation between them and humans in terms of entanglement. This need is quite understandable if we consider the issue of plastics (Hawkins, 2017a, b) and, in particular, the ubiquity of micro-plastics: they can now be found in oceans, freshwater lakes, air, fish, birds, mosquitoes - and human bodies are no exception. Our bodily systems are inextricably intertwined with the micro-plastics that have entered them. Post-masculinist rationality might help in tackling this kind of situation. It calls for a different understanding of rationality, one that is 'always already embodied and immersed, responding to the call of matter and to its various materialisations - materialisations such as humans, animals, plants, inanimate objects, as well as the relations between them' (Zylinska, 2014, pp. 14-15).

The chapters in this book provide several examples of how humans and more-than-humans coexist and entangle. Chapter 2, by Clingerman, while deliberating on the imaginative and conceptual effects of the Anthropocene in the political sphere, argues that "we must discover ways to "re-place" the Anthropocene within the task of imagination and our future, and to 
do so in a way that engages the complexity and uniqueness of human and more-than-human communities'. This complexity and uniqueness are empirically demonstrated by Rantala, Valtonen and Salmela (Chapter 3), who explore the ways in which humans and rocks relate and intertwine in the context of a national park. They accord agency to rocks and demonstrate how they are intertwined with embodied and affective human knowers, both shaped by and shaping them. This way of thinking allows them to offer a complex picture of how more-than-human care is articulated in that particular context.

Giovanni Frigo (Chapter 8) sets out to explore the transition of energy from fossil fuels to renewable and sustainable energy sources. His conceptual study starts from the premise that such a transition implies the transformation of complex energy systems and is intertwined with a range of economic, gendered, socio-political, religious and eco-systemic dimensions. To grasp this complexity, he coins the term 'human-energy-nature relationship' to highlight how various biological and cultural relations are embedded in it. Such a notion, he suggests, facilitates a reorientation toward eco-centric understanding. Thus, Frigo claims that we need to recognise the intrinsic value of the more-than-human inhabitants of the earth, listing the possible effects of this recognition on environmental law.

Chapter 9, by Jana Lozanoska, employs Hannah Arendt's political theory to analyse the intersection between temporality, technology and justice in the Anthropocene. Starting from the premise that growing technological developments have shifted conceptions of humanity, the chapter focuses on Arendt's concept of 'non-time space' to explore the idea of justice, suggesting that it is in this small crack of time and space that a temporality of judgement occurs. The chapter elaborates that technology relates to public space, politics and justice itself. It does not lean on the techno-utopic narrative that casts technology as a means to tackle environmental problems, but rather it suggests that unpredictable new beginnings play a crucial part in the human condition of plurality, which is characterised by apolitical freedom and political equality, a concept Arendt attempts to teach us.

\section{STRUCTURE OF THE BOOK}

Taken together, the contributions to this book provide a diverse, timely and perhaps provocative set of perspectives on the Anthropocene. The contributors come from a number of different disciplinary backgrounds, including law, organisational studies, tourism studies, philosophy, cultural geography, political sciences and international relations.

The chapters are grouped into three thematic parts. The first part of the book - Reimaginations - opens up the conceptual landscape of the debates surrounding the Anthropocene and reveals pathways to reimaginations. First, 
in Chapter 2, Clingerman provides an up-to-date critique of the concept of the Anthropocene, discussing its legacies and challenges, as well as its potentialities for and reimaginations of thinking about place and space in the Anthropocene. Second, Rantala, Valtonen and Salmela discuss in Chapter 3 how the concept of care must be reimagined when it is applied to the local context of 'walking-with' rocks in an Arctic region. They thereby provide a contextual, micro-level analysis of more-than-human care, with the help of a novel method. Third, in Chapter 4, Höckert sets out to reimagine the practice of storytelling and story-listening, deliberating on the ways in which scientific fables allow us to gather around matters of care in more-than-human worlds. The introduced conceptual innovation of scientific fabulation allows multiple voices to be involved in the narrative of the Anthropocene, regarding complicating, specifying, slowing down and hesitating as important aspects of narration.

The second part of this book - Stories from Marginalised Communities - presents studies conducted within marginalised communities in the global south, namely Bangladesh and India. It grants voices to often-silenced and marginalised groups, such as poor peasants, displaced people, slum communities and indigenous people. By providing down-to-earth analyses of everyday struggles, conflicts, social movements, interventions and grassroots activism enacted in these vulnerable contexts, the chapters by Khanem and Seppälä (Chapter 5), Routledge (Chapter 6) and Bisht (Chapter 7) render visible the experiences of people affected by the practices of the economic and political elite (such as mining, 'development' or biotechnologies), demonstrating how marginalised people take agency to respond to the exploitation they face. These studies also render visible worldviews that portray nature-culture relations beyond monetary terms, thereby opening up a different system of belief that merits respect. In so doing, this part develops a view of epistemology that values non-Western local knowledge and know-how, questioning the epistemic privilege of scientific knowledge.

The third part of this book - Law and Technology - takes up the issues of technology, law and justice, pondering their significant yet changing role in the debates surrounding the Anthropocene. The contributions of this part lean on different theoretical perspectives to reimagine prevalent ways of thinking about key concepts and practices. For instance, in Chapter 8, Frigo employs a philosophical perspective to reimagine the energy transition from fossil fuels to renewable energy sources. Through the term human-energy-nature relationship, he captures the complexity of various biological and cultural relations embedded in the use of energy. As such, he facilitates a reorientation of the human-energy-nature relationship toward eco-centric understanding. In Chapter 9, Lozanoska mobilises Hannah Arendt's work to analyse the intersection between temporality, technology and justice in the Anthropocene. 
Assuming first that growing technological developments have transformed conceptions of humanity, the chapter takes up Arendt's concept of non-time space to explore the idea of justice: it is in this small crack of time and space that a temporality of judgement occurs. Farah and Prityi (Chapter 10) introduce the age of the Anthropocene through reference to both the warnings of expert reports and the urgency of several challenges associated with the epoch. They describe the challenges and implications that such climatic chaos presents for governance and how such unprecedented challenges must be tackled by agile governance systems that include a broad array of stakeholders from both vertical and horizontal governance backgrounds, ranging from local, state, national and international levels to the private, public and NGO sectors. Chapter 11 by Farah wraps up the contents of the volume by discussing the ways in which the approach proposed in the book contributes to the debate on the Anthropocene.

\section{REFERENCES}

Alaimo, S., \& Hekman, S. (2008). Material feminism. Indiana University Press.

Angus, I. (2016). Facing the Anthropocene: Fossil capitalism and the crisis of the earth system. Monthly Review.

Barad, K. (2003). Posthumanist performativity: Toward an understanding of how matter comes to matter. Signs: Journal of Women in Culture and Society, 28(3), 801-831. https://doi.org/10.1086/345321.

Beacham, J. (2018). Organising food differently: Towards a more-than-human ethics of care for the Anthropocene. Organization, 25(4), 533-549. https://doi.org/10.1177/ 1350508418777893.

Bennett, J. (2010). Vibrant matter. Duke University Press.

Biermann, F. (2014). Earth system governance: World politics in the Anthropocene. MIT Press.

Biermann, F., Bai, X., Bondre, N., Broadgate, W., Chen-Tung, A., Dube, O. P., Willem Erisman, J., Sandravan der Hel, M. G., Seitzinger, M. C., \& Seto, K. C. (2016). Down to earth: Contextualizing the Anthropocene. Global Environmental Change, 39(July), 341-350. https://doi.org/10.1016/j.gloenvcha.2015.11.004.

Bonnedahl, K. J., \& Heikkurinen, P. (Eds). (2018). Strongly sustainable societies: Organizing human activities on a hot and full earth. Routledge.

Clark, N., \& Yusoff, K. (2017). Geosocial formations and the Anthropocene. Theory, Culture and Society, 34(2-3), 3-23. https://doi.org/10.1177\%2F0263276416688946.

Crutzen, P. J. (2002). Geology of mankind: The Anthropocene. Nature, 415(6867), 23. https://doi.org/10.1038/415023a.

Crutzen, P. J., \& Stoermer, E. F. (2000). Have we entered the 'Anthropocene'? IGBP Global Change Newsletter, 41, 17.

Cui, Q., \& Xu, H. (2019). Situating animal ethics in Thai elephant tourism. Asia Pacific Viewpoint, 60(3), 267-279. https://doi.org/10.1111/apv.12221.

Frost, S. (2016). Biocultural creatures: Towards a new theory of the human. Duke University Press.

Grusin, R. (2017). Anthropocene feminism. University of Minnesota Press.

Hamilton, C. (2016). The Anthropocene as rupture. The Anthropocene Review, 3(2), 93-106. https://doi.org/10.1177\%2F2053019616634741. 
Haraway, D. (2016). Staying with the trouble: Making kin in the Chthulucene. Duke University Press.

Hawkins, G. (2017a). Plastics. In I. Szeman, J. Wenzel, \& P. Fordham Yaeger Fordham (Eds), Fueling culture: 101 words for energy and environment (pp. 271-274). Fordham University Press.

Hawkins, G. (2017b). Ethical blindness: Plastics, disposability and the art of not caring. In V. Kinnunen \& A. Valtonen (Eds), Living ethics (pp. 15-28). University of Lapland.

Heikkurinen, P. (Ed.). (2017). Sustainability and peaceful coexistence for the Anthropocene. Routledge.

Jickling, B., Blenkinsop, S., Timmerman, N., \& De Danann Sitka-Sage, M. (Eds). (2018). Wild pedagogies: Touchstones for re-negotiating education and the environments in the Anthropocene. Palgrave Macmillan.

Kalonaityte, V. (2018). When rivers go to court: The Anthropocene in organization studies through the lens of Jacques Ranciere. Organization, 25(4), 517-532. https:// doi.org/10.1177\%2F1350508418775830.

Kinnunen, V., \& Valtonen, A. (Eds). (2017). Living ethics in a more-than-human world. University of Lapland.

Lorimer, J. (2015). Wildlife in the Anthropocene: Conservation after nature. University of Minnesota Press.

Loveless, N. (2019). How to make art at the end of the world: A manifesto for research-creation. Duke University Press.

Malm, A. (2016). Fossil capital: The roots of steam power and the roots of global warming. Verso.

Malm, A., \& Hornborg, A. (2014). The geology of mankind? A critique of the Anthropocene narrative. The Anthropocene Review, 1(1), 62-69. https://doi.org/10 $.1177 \% 2 F 2053019613516291$.

Moore, J. W. (Ed.). (2016). Anthropocene or capitalocene? Nature, history, and the crisis of capitalism. PM Press.

Motta, S. (2011). Notes towards prefigurative epistemologies. In S. C. Motta \& A. G. Nilsen (Eds), Social movements in the global south: Dispossession, development and resistance in the global south (pp. 178-199). Palgrave Macmillan.

Palsson, G., \& Swanson, H. A. (2016). Down to earth: Geosocialities and geopolitics. Environmental Humanities, 8(2), 149-171. https://doi.org/10.1215/22011919 -3664202 .

Palsson, G., Szerszynski, B., Sörlin, S., Marks, J., Avrile, B., Crumley, C., Hackmanng, H., Holm, P., Ingram, J., Kirman, A., Buendía, M. P., \& Weehuizenl, R. (2013). Reconceptualizing the 'anthropos' in the Anthropocene: Integrating the social sciences and humanities in global environmental change research. Environmental Science and Policy, 28(April), 3-13. https://doi.org/10.1016/j.envsci.2012.11.004.

Puig de la Bellacasa, M. (2012). 'Nothing comes without its world': Thinking with care. The Sociological Review, 60(2), 197-216. https://doi.org/10.1111\%2Fj.1467 -954X.2012.02070.x.

Puig de la Bellacasa, M. (2015). Making time for soil: Technoscientific futurity and the pace of care. Social Studies of Science, 45(5), 691-716. https://doi.org/10.1177 \%2F0306312715599851.

Rantala, O., Höckert, E., \& Ilola, H. (2019). 'Knowing-with' in the era of the Anthropocene. Matkailututkimus, 15(2), 4-8. https://doi.org/10.33351/mt.88263. 
Salmela, T., \& Valtonen, A. (2019). Towards collective ways of knowing in the Anthropocene: Walking-with multiple others. Matkailututkimus, 15(2), 18-32. https://doi.org/10.33351/mt.88267.

Salminen, A., \& Vaden, T. (2015). Energy and experience: An essay on naftology. M.C.M.

Schmidt, J. J., Brown, P. G., \& Orr, C. J. (2016). Ethics in the Anthropocene: A research agenda. The Anthropocene Review, 3(3), 188-200. https://doi.org/10 $.1177 \% 2 F 2053019616662052$.

Seppälä, T. (2016). Feminizing resistance, decolonizing solidarity: Contesting neoliberal development in the global south. Journal of Resistance Studies, 2(1), 12-47.

Springgay, S., \& Truman S. E. (2018). Walking methodologies in a more-than-human world: WalkingLab. Routledge.

Toivanen, T., Lummaa, K., Majava, A., Järvensivu, P., Lähde, V., Vaden, T., \& Eronen, T. J. (2017). The many Anthropocenes: A transdisciplinary challenge for the Anthropocene research. The Anthropocene Review, 4(3), 183-198. https://doi.org/10 $.1177 / 2053019617738099$.

Tsing, A. L. (2017). The mushroom at the end of the world: On the possibility of life in capitalist ruins. Princeton University Press.

Ulmer, J. B. (2017). Posthumanism as research methodology: Inquiry in the Anthropocene. International Journal of Qualitative Studies in Education, 30(9), 832-838. https://doi.org/10.1080/09518398.2017.1336806.

Wright, C., Nyberg, D., Rickards, L., \& Freund, J. (2018). Organizing in the Anthropocene. Organization, 25(4), 455-471. https://doi.org/10.1177 \%2F1350508418779649.

Yusoff, K. (2016). Anthropogenesis: Origins and endings in the Anthropocene. Theory, Culture and Society, 33(2), 3-28. https://doi.org/10.1177\%2F0263276415581021.

Yusoff, K., \& Gabrys, J. (2011). Climate change and the imagination. WIREs Climate Change, 2(4), 516-534. https://doi.org/10.1002/wcc.117.

Zylinska, J. (2014). Minimal ethics for the Anthropocene. Open Humanities Press. 